\title{
10 Queerness in the US agrifood system during COVID-19
}

\author{
Michaela Hoffelmeyer
}

\section{Introduction}

Although research and data frequently erase queer people in agriculture, queer people engage in all aspects of the agrifood system, from the farm as farmworkers and farmers - to the table - as restaurant workers, owners, and consumers. As such, there is no singular queer agricultural pandemic experience. This chapter outlines the multifaceted ways that COVID-19 impacts queer people at various points in the United States' agrifood system. I emphasize that queer food workers and farmworkers' experiences are influenced by intersections of race, ethnicity, class, and gender as queerness traverses these identities. I highlight how continued disparities in healthcare, economics, and social support call for policies that attend to this heterogeneous group, especially in times of crisis.

\section{Food and farmworkers}

For essential workers in the agrifood system, the pandemic poses a doubleedged sword. Employment provides income and potentially access to health insurance, but working in fields, processing plants, and restaurants with limited personal protective equipment and inadequate worker safety protocols poses health risks. At the same time, losing jobs or withdrawing from unsafe work conditions may allow these people to avoid COVID-19 at the expense of losing vital income. Agrifood system workers face a higher risk of being exposed to COVID-19 due to the essential nature of their work. For queer people in these jobs, if exposed, there is a significant risk of becoming seriously ill as queer populations face higher rates of poverty and less access to medical care than their heterosexual peers (Whittington, Hadfield, and Calderón, 2020) (Figure 10.1). 


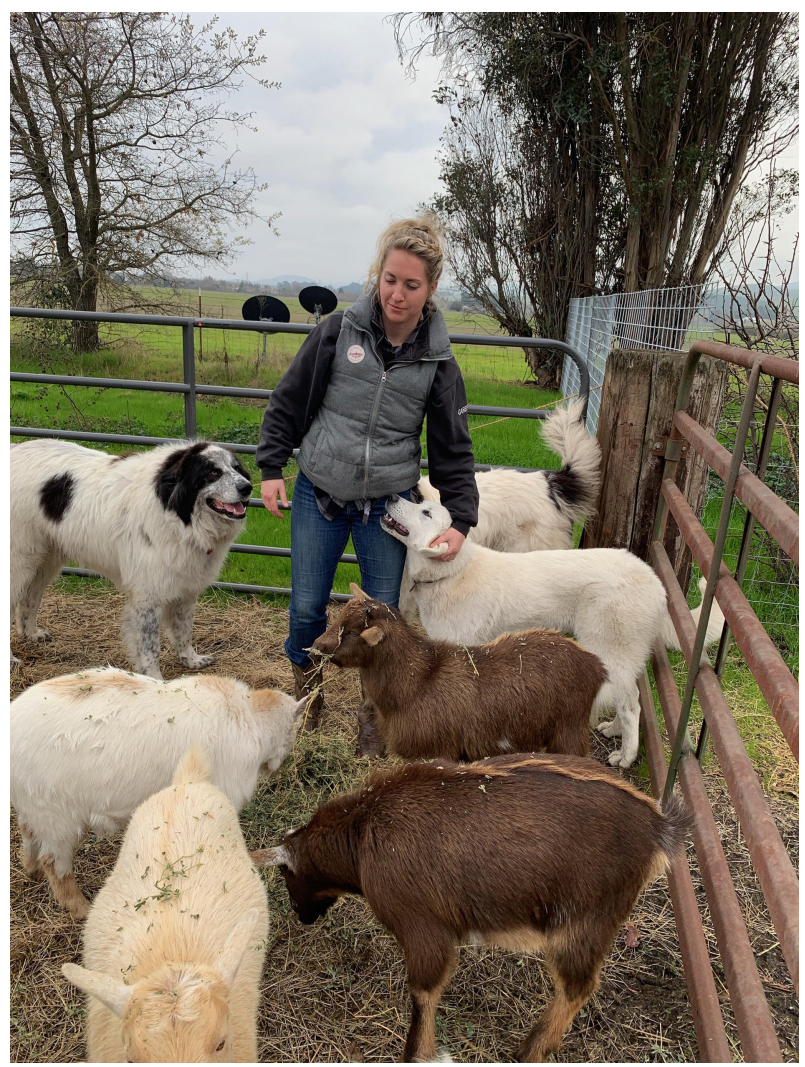

Figure 10.1 Queer farmer, Alysha Gareis, tends the livestock on California farm. During 2020, intense wildfires and COVID-19 forced significant shifts in farmers' market safety protocols and threatened Alysha's employment options (Alysha Gareis).

\section{Farmworkers}

Farmworkers are the foundation of the food system and have been deemed "essential" during COVID-19 despite frequently experiencing racism and xenophobia (Holmes, 2013). Of the 2.4 million farmworkers in the United States (Farmworker Justice, 2018) there is no count of the number of queer farmworkers, but they are in the fields and sharing their stories (Lizarazo et al., 2017). In addition to healthcare barriers faced by all farmworkers (e.g., cost, access, fear of employer retaliation), queer farmworkers face stigma and fear for revealing their identity in healthcare settings, potentially placing 
them at higher risk for adverse health outcomes (National LGBT Health Education Center and Farmworker Justice, 2015). For farmworkers during the pandemic, the combined heteronormativity and heterosexism in agriculture and healthcare may result in underdiagnosing and insufficient tracing of COVID-19 (Wypler and Hoffelmeyer, 2020). The National LGBT Health Education Center's policy brief lays out best practices for health centers to build trust with queer farmworkers, such as inclusive language and availability of sexual health screenings (National LGBT Health Education Center and Farmworker Justice, 2015). As farmworkers are required to continue working during this time of increased health risks, healthcare facilities must adopt these best practices to support queer farmworkers' well-being.

\section{Meat processing workers}

In ethnographic fieldwork in the rural South, Ribas (2016) notes a surprising number of queer employees, particularly African Americans, involved in meat processing. COVID-19 has been particularly devastating for meat processing workers (Douglas, 2020). Meat processing facilities remain hotbeds for COVID-19 due to poor working conditions that require close and prolonged contact among workers and slow implementation of safety protocols from companies. Inadequate medical care, lack of paid time off, and low wages in this industry are exacerbated by heterosexism. Compared to heterosexual populations, queer populations report avoiding seeking medical attention because of costs and discrimination (Whittington, Hadfield, and Calderón, 2020). When considered alongside existing research documenting meat processing workers' injury rates (Horowitz, 2008), queer people in this industry may face additional hurdles to remaining safe and healthy during the pandemic.

\section{Restaurant workers}

Restaurant and food services represent the highest employment industry of queer people (Whittington, Hadfield, and Calderón, 2020). Approximately 2 million queer people work in this industry, representing 15 percent of the queer population (Whittington, Hadfield and Calderón, 2020). During the pandemic, restaurant and food service workers lost their jobs or experienced severely reduced hours, thereby increasing economic insecurity for this population. Because healthcare in the United States is tied to work, the loss of employment is further devastating during the pandemic. Because queer people work in service industries at higher rates than their heterosexual peers (Whittington, Hadfield, and Calderón, 2020), the pandemic's impact on the restaurant and food service industry has likely unevenly impacted queer populations. 


\section{Food and farmworker considerations}

Federal financial and health support misses populations, in particular undocumented immigrants who are heavily involved in food production (Holmes, 2013), processing (Ribas, 2016), and service (Jayaraman, 2013). Being queer and undocumented can compound existing healthcare inequalities. For example, immigrant workers, in particular undocumented workers, in farming, meat processing, and food services remain at work even when sick, due to low pay, lack of paid sick time, and fear of employer retaliation (Holmes, 2013; Jayaraman, 2013; Ribas, 2016). Additionally, queer workers report fears of discrimination that prevent them from requesting leave if required to disclose their identity (Whittington, Hadfield, and Calderón, 2020). During COVID-19, queer workers, particularly those in precarious employment, may be hesitant to report exposure to or contraction of COVID-19 due to any combination of social location factors. Considering sexuality and gender identity along with health risks associated with immigration status, race, and ethnicity, offers the potential to understand the experiences of these populations more fully. Given the multiplying effects of COVID-19, this pandemic demonstrates the power of centering the health and well-being of the most vulnerable in the agrifood system as a necessary means of facilitating safe and reliable production, processing, and distribution of food (Wypler and Hoffelmeyer, 2020) (Figure 10.2).

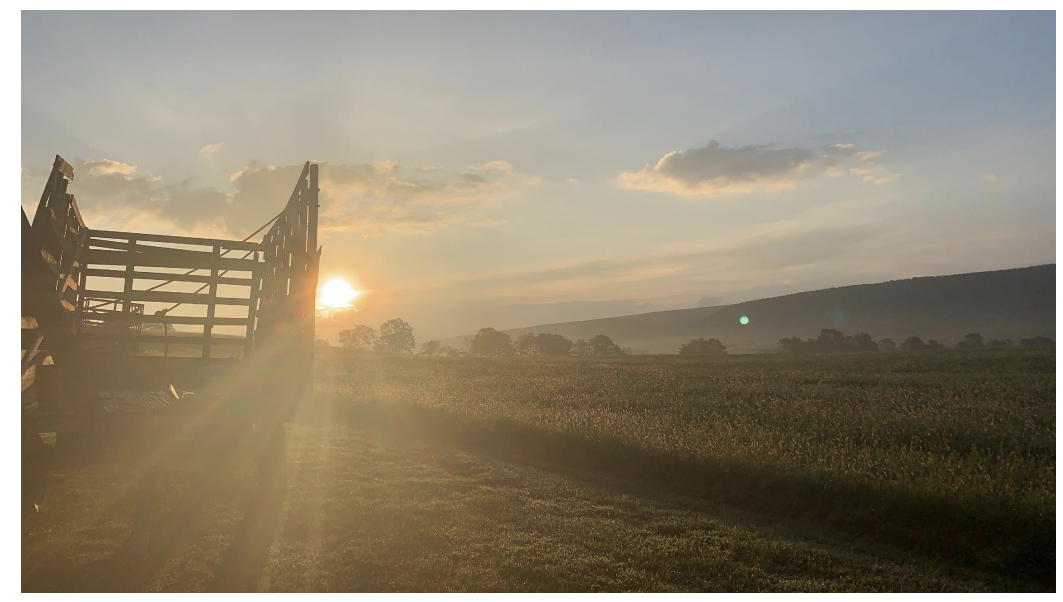

Figure 10.2 Farm sunrise on a queer-owned farm in Pennsylvania, captured during morning chores (Michaela Hoffelmeyer). 


\section{Farm owners}

The queer community is no stranger to being physically distant and isolated from social support as our fellow queers and chosen family are often geographically dispersed. For queer farmers, in-person queer-centered events offer a chance to relieve social and physical isolation and develop economic networking opportunities (Wypler, 2019). Queer community gatherings offer a place of vital respite and networking, especially for queer people navigating heterosexism in agriculture (Hoffelmeyer, 2020). However, many of these in-person meetings were canceled due to the pandemic. The loss of social support, knowledge transfer, and networking due to COVID19 is immeasurable.

Queer farmers during COVID-19 face increased mental health stressors related to the loss of in-person social networking and support (Wypler and Hoffelmeyer, 2020), as both the queer (Salerno, Williams and Gattamorta, 2020) and farmer (Inwood et al., 2019) populations face higher mental health risks compared to the general population in non-pandemic times. However, because queer farmers have formed resilience social support networks in the face of anticipated heterosexism, queer farmers may have insulated themselves against some adverse mental health impacts during the pandemic (Wypler and Hoffelmeyer, 2020). As such, while mental health and support networks are critical for all farmers, queer farmers offer new insights about the role of building collective, wide-ranging community support systems that can weather existing inequalities and offer protection under increased stress during the pandemic and potentially other extreme events such as climate change.

\section{Farm policy}

Queer farmers, often small-scale and sustainable, have unique policy needs that cannot be assumed to be addressed through sweeping legislation. During COVID-19, small-scale farms with already tight profit margins are rapidly adjusting to online sales, increased safety measures, and lost wholesale and event revenue. Despite experiencing financial hardship, small-scale farms rarely receive adequate financial support compared to large-scale commodity farms. Federal farm subsidy programs direct aid toward the wealthiest farms (Schechinger, 2021). Under the Trump administration, the Coronavirus Financial Assistance Program aimed to support agricultural producers but likely missed small farmers due to challenges accounting for losses of direct sales and costs associated with diversified production (Crampton, 2020). While data is still emerging, through June of 2020, nearly 24 percent of farm subsidies went to the top 1 percent of farms, and approximately 64 percent 
of subsidies went to the top 10 percent (Schechinger, 2021). Rather than continuing the status quo of disproportionately supporting large-scale commodity producers, funds directed toward small-scale producers are critical for agrifood system resilience, particularly in times of crisis.

Farm scale and identity are tightly interconnected. Government aid funneled toward large-scale producers means that men - often white and likely heterosexual - reap the benefits of US farm subsidies (Sachs et al., 2016), predominantly because crop subsidies favor wheat, corn, grain, and other staple crops (Howard, 2016), and men tend to be engaged in highly mechanized, capital-intensive production (Sachs et al., 2016). As such, COVID-19 farm aid should center socially disadvantaged farmers. The US Department of Agriculture (USDA) has a history of discrimination against minorities, including Blacks, Hispanics, and women (Carpenter, 2012). In the wake of COVID-19, small farms may benefit from increased customer interest in sourcing food directly from farmers. However, these farmers may ultimately be excluded from government support if programs are not specifically geared to underserved farming populations. Unlike race, ethnicity, and (cis)gender, the USDA does not consider queer (not heterosexual and/or cis-gender) farmers to be an underserved population. Qualitative research demonstrates that queer farmers face barriers in accessing government farming assistance (Leslie, 2017). Therefore, in addition to COVID-19 farm aid being directed to underserved farming groups, USDA programs should expand to include support for queer farmers as heterosexism has been documented in agriculture. While the Biden administration shows promise for supporting the distribution of financial resources to Black farmers (Walljasper, 2021), long-term structural changes confronting concentration in land, decision-making, and power in agriculture will be required to deter the high levels of inequitable distribution of resources and injustices currently existing in agriculture (Hendrickson et al., 2020) (Figure 10.3).

\section{Consumers}

Queer consumers experience disproportionate levels of food insecurity and Supplemental Nutrition Assistance Program (SNAP) participation outside of global pandemics (Brown, Romero and Gates, 2016). In 2016, approximately 17 percent of heterosexual adults experienced a time when they did not have enough money to feed themselves or their families; that number was $27 \%$ - or 2.2 million people - for queer adults (Brown, Romero and Gates, 2016). Within the queer community, food access is unevenly distributed by race and ethnicity as 42 percent of African Americans, 33 percent of Hispanics, 32 percent of American Indians and Alaskan Natives, and 21 percent of Whites reported not having enough money to feed themselves or 
Queerness in the US agrifood system 95

their families (Brown, Romero and Gates, 2016). Efforts to expand SNAP and provide emergency food access must confront the existing inequalities in food access.

\section{Conclusion}

This chapter demonstrates queer people's involvement in every facet of the agrifood system from farm to table. While heterosexism and heteronormativity make this population seemingly invisible, considering the unique needs of queer populations remains vital for addressing inequalities and injustices in the agrifood system. Recognizing the critical role of gender and sexuality,

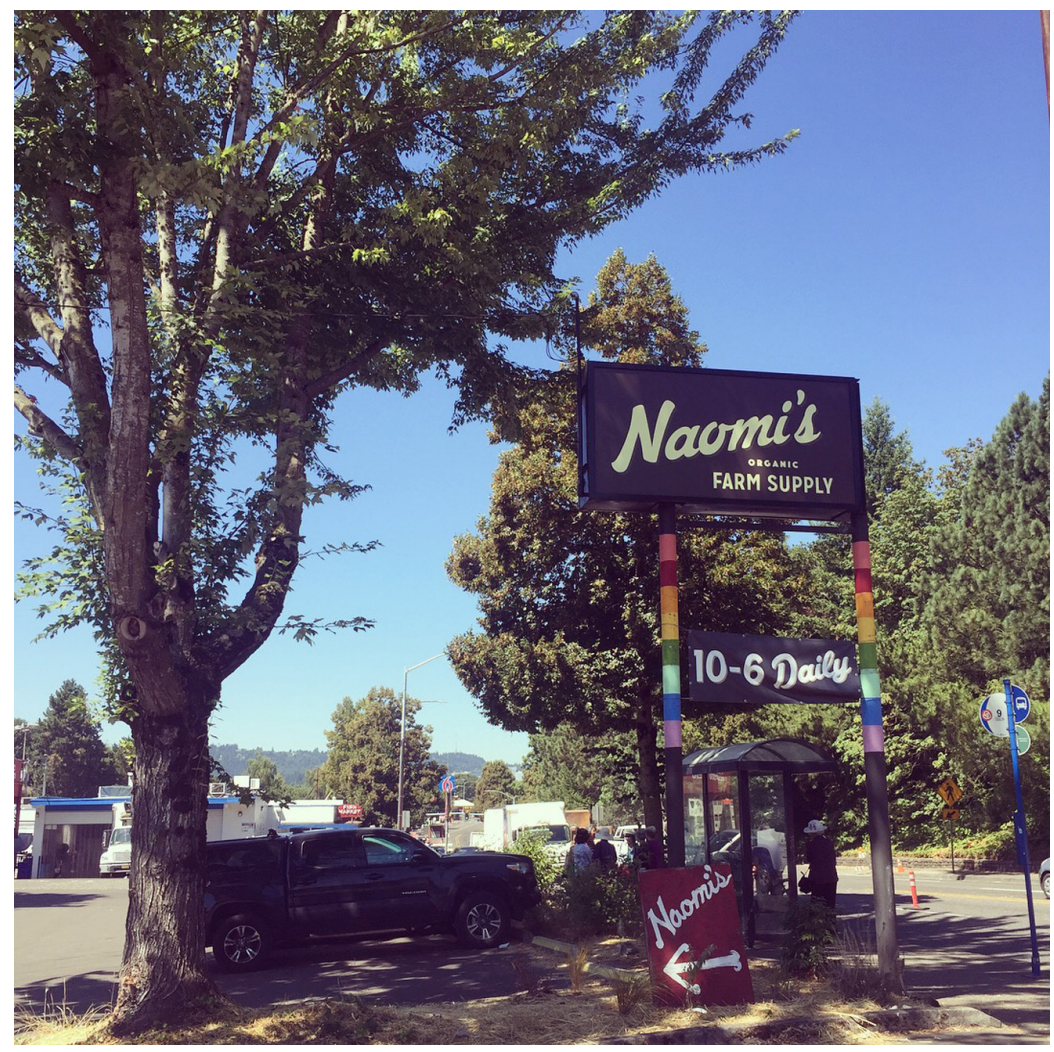

Figure 10.3 Naomi's Organic Farm Supply, Portland, Oregon, operated for over 11 years but closed in 2021 after dramatic shifts in safety protocols and sales operations due to the pandemic (Michaela Hoffelmeyer). 
queer people in the agrifood system have mobilized during COVID-19. For example, Rock Steady Farm, a revolutionary, highly visible queer-owned farm in rural New York, worked before and throughout the pandemic to meet the needs of queer and BIPOC (Black, indigenous, people of color) customers and farmers. Rock Steady makes nutrient-dense food available to BIPOC, queer, and low-income communities through the farm's innovative slidingscale Community Supported Agriculture model and Food Sovereignty Fund. In 2020 at the height of the pandemic, 57 percent of food grown at Rock Steady went to low-income consumers, representing approximately 52,000 meals and 35,000 pounds of produce (Rock Steady Farm \& Flowers, n.d.). Additionally, Rock Steady's farmer training and land access partnerships promote long-term, sustainable shifts in the agrifood system (Rock Steady Farm \& Flowers, no date). By creating a safe, supportive farm where BIPOC and queer farm employees can learn valuable farming skills, Rock Steady's model counters racism and heterosexism in farming, which can deter farmers' long-term involvement in agriculture (Hoffelmeyer, 2021). Working against exploitative models by privileging farm employees' livable wages and making significant efforts during COVID-19 to protect farmers' safety, Rock Steady illustrates one farming model that confronts rather than replicates injustices.

Other efforts to support queer community health include the Out in the Open organization, the Okra Project, and the Queer Food Foundation. First, the rural queer grassroots organization, Out in the Open, located in Vermont, developed online programing and support groups to relieve isolation and promote organizing around rural trans and queer health. Out in the Open hosted a virtual meeting for queer farmers to gather and network about the impacts of COVID-19 (Out in the Open, n.d.). Second, The Okra Project works in New Jersey, Philadelphia, and New York to address food and economic inequalities faced by Black Trans people. Early in the pandemic, the organization expanded its international grocery fund in anticipation of increased need. Adjusting to COVID-19 and Center for Disease Control guidelines, the organization plans to revive its Direct Chef Services program during 2021, which hires Black Trans chefs to prepare nutritious and culturally specific meals delivered directly to Black Trans people (The Okra Project, n.d.). Finally, the Queer Food Foundation aims to "promote, protect, fund, and create queer food spaces; to acknowledge, celebrate, and honor queer food workers and chefs." Founded in 2020, the Queer Food Foundation has begun creating a queer food database and developed the Queer Food Fund, a community mutual aid project redistributing donations to the Black Queer community facing food insecurity (Queer Food Foundation, no date).

These are simply a few examples of queer people resisting oppression and marginalization embedded in the agrifood system. As non-profit 
organizations, these examples illustrate how federal and state-level support is insufficient. Pivoting to meet community members' needs during the pandemic, these organizations are filling critical roles. However, longterm changes to the agrifood system requires attention to the distribution of access to land, labor, and knowledge at all levels of agricultural production with attention to racism, classism, sexism, and heterosexism (Leslie, 2019).

COVID-19 exposed the numerous cracks in the standardized global food system (Hendrickson, 2020), yet the shortcomings of the current agrifood system were already visible to those experiencing food injustices. While COVID-19 data is still emerging, trends show that Black, Indigenous, Hispanic (Wood, 2020), and queer communities (National LGBT Cancer Network, 2020) are disproportionately affected. Moving forward, policies that center these communities' insights and perspectives on food production and access will be critical to bolstering resilience and sustainability in the agrifood system.

\section{References}

Farmworker Justice (2018) Selected Statistics on Farmworkers. Available at: https:// www.farmworkerjustice.org/sites/default/files/resources/NAWSdatafactsht10 -18-18.pdf.

Brown, T. N. T., Romero, A. P. and Gates, G. J. (2016) Food Insecurity and SNAP Participation in the LGBT Community, The Williams Institute, UCLA School of Law. Available at: http://williamsinstitute.law.ucla.edu/wp-content/uploads/ Food-Insecurity-and-SNAP-Participation-in-the-LGBT-Community.pdf.

Carpenter, S. (2012) 'The USDA Discrimination Cases: Pigford, In Re Black Farmers, Keepseagle, Garcia, and Love', Drake Journal of Agricultural Law, 17(1), pp. 1-36.

Crampton, L. (2020) Young Farmers Worry About Access to USDA Aid, Politico. Available at: https://www.politico.com/newsletters/morning-agriculture/2020 /05/29/young-farmers-worry-about-access-to-usda-aid-788003.

Douglas, L. (2020) Mapping Covid-19 in Meat and Food Processing Plants, Food and Environment Reporting Network. Available at: https://thefern.org/2020/04/ mapping-covid-19-in-meat-and-food-processing-plants/.

Hendrickson, M. K. (2020) 'Covid Lays Bare the Brittleness of a Concentrated and Consolidated Food System', Agriculture and Human Values, 37, pp. 579-580. https://ink.springer.com/article/10.1007\%2Fs10460-020-10092-y\#citeas.

Hendrickson, M. K. et al. (2020) The Food System: Concentration and Its Impacts, Family Farm Action Alliance. Available at: https://farmactionalliance.org/ concentrationreport/.

Hoffelmeyer, M. (2020) 'Queer Farmers: Sexuality on the Farm', in Sachs, C. et al. (eds) Gender and Agriculture Handbook. New York: Routledge, pp. 348-359. 
Hoffelmeyer, M. (2021) "'Out" on the Farm: Queer Farmers Maneuvering Heterosexism and Visibility', Rural Sociology. Available at: https:/onlinelibrary. wiley.com/doi/full/10.1111/ruso.12378?casa token=F67_U7vGT3wAAAAA\% 3A9FBXtiISNG64Dv3Q1IbaJRV7t73B_pGLQYW4ZvenBcNTNvua7X-2QI Rsavs0_SW9cvJAyQQ-YOTEWQ.

Holmes, S. (2013) Fresh Fruit, Broken Bodies: Migrant Farmworkers in the United States. Berkeley, CA: University of California Press.

Horowitz, R. (2008) “"That Was a Dirty Job!” Technology and Workplace Hazards in Meatpacking over the Long Twentieth Century', Labor: Studies in Working-Class History of the Americas, 5(2), pp. 13-25. doi: 10.1215/15476715-2007-075.

Howard, P. (2016) Concentration and Power in the Food System: Who Controls What We Eat? New York: Bloomsbury.

Inwood, S. et al. (2019) 'Responding to Crisis: Farmer Mental Health Programs in the Extension North Central Region', Journal of Extension, 57(6). Available at: https://openprairie.sdstate.edu/cgi/viewcontent.cgi?article=1078\&context= chd_pubs.

Jayaraman, S. (2013) Behind the Kitchen Door. Ithaca: Cornell University Press.

Leslie, I. S. (2017) 'Queer Farmers: Sexuality and the Transition to Sustainable Agriculture', Rural Sociology, 82(4), pp. 747-771. doi: 10.1111/ruso.12153.

Leslie, I. S. (2019) 'Queer Farmland: Land Access Strategies for Small-Scale Agriculture', Society and Natural Resources. Routledge, 32(8), pp. 928-946. doi $: 10.1080 / 08941920.2018 .1561964$.

Lizarazo, T. et al. (2017) 'Ethics, Collaboration, and Knowledge Production: Digital Storytelling with Sexually Diverse Farmworkers in California', Lateral, 6(1). Available at: https://mdsoar.org/handle/11603/19531.

National LGBT Cancer Network (2020) Coronavirus Information. Available at: https://cancer-network.org/coronavirus-2019-1gbtq-info/.

National LGBT Health Education Center and Farmworker Justice (2015) Promoting Health Care Access to Lesbian, Gay, Bisexual, and Transgender (LGBT) Farmworkers. Available at: https://www.farmworkerjustice.org/sites/default/ files/FJ-LGBTHealthEducationCenterIssueBrief FINAL.pdf.

Out in the Open (no date). Available at: https://www.weareoutintheopen.org/.

Queer Food Foundation (no date). Available at: https://queerfoodfoundation.org/.

Ribas, V. (2016) On the line: Slaughterhouse Lives and the Making of the New South. Oakland, CA: University of California Press.

Rock Steady Farm \& Flowers (no date). Available at: https://www.rocksteadyfarm .com/.

Sachs, C. et al. (2016) The Rise of Women Farmers and Sustainable Agriculture. Iowa City: University of Iowa Press.

Salerno, J. P., Williams, N. D. and Gattamorta, K. A. (2020) "LGBTQ Populations: Psychologically Vulnerable Communities in the COVID-19 Pandemic," Psychological Trauma: Theory, Research, Practice, and Policy, 12, pp. 239242. doi: $10.1037 /$ tra0000837.

Schechinger, A. (2021) Under Trump, Farm Subsidies Soared and the Rich Got Richer Biden and Congress Must Reform a Wasteful and Unfair System. Available 
at: https://www.ewg.org/interactive-maps/2021-farm-subsidies-ballooned-under -trump/.

The Okra Project (no date). Available at: https:/www.theokraproject.com/.

Walljasper, C. (2021) "U.S. Lawmakers Introduce Legislation to Help Black Farmers," Reuters. Available at: https://www.reuters.com/article/us-usa -agriculture-relief/u-s-lawmakers-introduce-legislation-to-help-black-farmers -idUSKBN2A9333.

Whittington, C., Hadfield, K. and Calderón, C. (2020) The Lives and Livelihoods of Many in the LGBTQ+ Community Are at Risk Amidst COVID-19 Crisis, Human Rights Campaign. Available at: https://assets2.hrc.org/files/assets/resources /COVID19-IssueBrief-032020-FINAL.pdf?_ga=2.235306753.1276285206 .1615311115-319094525.1614199648

Wood, D. (2020) As Pandemic Deaths Add Up, Racial Disparities Persist - And In Some Cases Worsen, NPR. Available at: https:/www.npr.org/sections/health -shots/2020/09/23/914427907/as-pandemic-deaths-add-up-racial-disparities -persist-and-in-some-cases-worsen?t=1608509692531\&t=1612998003537.

Wypler, J. (2019) "Lesbian and Queer Sustainable Farmer Networks in the Midwest," Society \& Natural Resources, 32(8), pp. 947-964. doi: 10.1080/08941920.2019.1584834.

Wypler, J. and Hoffelmeyer, M. (2020) "LGBTQ+ Farmer Health in COVID-19," Journal of Agromedicine, 25(4), pp. 370-373. doi: 10.1080/1059924X.2020. 1814923. 